\title{
Türk Sovyet İlişskileri Literatürüne Bir Katkı
}

\section{A Contribution to the Turkish-Soviet Relations Literature}

\section{Erdal Bilgiç, Erken Cumhuriyet Döneminde Türk Sovyet Ekonomik İlişkileri, 1. Baskı, İstanbul, Efil Yayınevi, 2021, 288 s.}

Efe GÜZELOĞLU* (D)

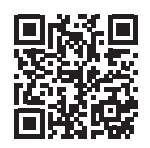

*Arş. Gör. , İstanbul Aydın Üniversitesi, Tarih Bölümü, İstanbul, Türkiye

ORCID: E.G. 0000-0002-2595-6645

Sorumlu yazar/Corresponding author: Efe Güzeloğlu,

İstanbul Aydın Üniversitesi, Tarih Bölümü, İstanbul, Türkiye

E-posta/E-mail: efeguzeloglu@aydin.edu.tr

Başvuru/Submitted: 15.10.2021

Kabul/Accepted: 15.12 .2021

Atıf/Citation: Guzeloglu, Efe. "Türk Sovyet İlişkileri Literatürüne Bir Katkı.” Erdal Bilgiç'in "Erken Cumhuriyet Döneminde Türk Sovyet Ekonomik îlişkileri" adlı eserinin değerlendirmesi." Yakın Dönem Türkiye Araştırmaları-Recent Period Turkish Studies 40 (2021): 313-318.

https://doi.org/10.26650/YTA2021-996217
Anahtar Kelimeler: Türk Sovyet İlişkileri, Ekonomik İlişsiler, Erken Cumhuriyet Dönemi, İki Savaş Arası Dönem, İktisat Tarihi

Keywords: Turkish Soviet Relations, Economic Relations, Early Republican Period, Interwar Period, Economic History

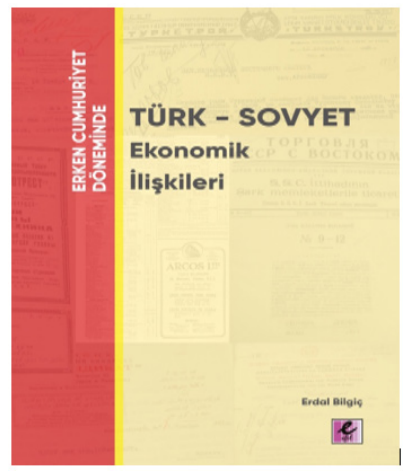




\section{Giriş}

Erdal Bilgiç'in Nisan 2021'de yayınlanan Erken Cumhuriyet Döneminde Türk Sovyet Ekonomik ilişkileri adlı çalışması, az çalışılan bir konuda son derece spesifik katkılar sunan ve literatürde önemli bir boşluğu dolduran bir eserdir. Kitap, yazarın Marmara Üniversitesi'nde tamamladığı doktora tezine dayanmaktadır. A ğırlıklı olarak Rus arşivlerinden çıkarılan birincil kaynakların detaylı bir şekilde kullanılmasıyla oluşturulan çalışma, kendi literatürü içinde istisnai bir örnek olmaya adaydır denebilir.

Kitabın tezlerine ve bunlar hakkında tartışmaya geçmeden önce kitabın kaynaklarını, literatüre katkısını ve önemini belirtmek faydalı olacaktır. Kitabın Rusça belgelere dayanan yapısı, alana birçok özgün bilgi getirmektedir. Gerek anlatının üzerine kuruldu$\breve{g u}$ geniş belge havuzu, gerekse yazarın sınırlı bir ikincil kaynak zeminine dayanması, kitabın eski bilgileri tekrarlayan bir yapıt olmasının önüne geçmiştir. Yazar literatürde önceden tartışılmış siyasi ve kültürel ilişkiler gibi konulara çok az değinmiş, iktisadi ilişkiler alanında literatürde büyük ölçüde ya da tamamen gözden kaçmış unsurları öne çıkarmıştır.

Burada önemli bir nokta, arşiv belgelerine dayanan bir çalışmada yalnızca Rus arşivlerinin verimli bir şekilde kullanılabilmiş olmasıdır. Yazarın kendisi de belirttiği gibi, Türk arşivindeki kaynaklar derinlikli bir iktisadi analize elverişli değildir. (s. 12) Türk - Sovyet ilişkilerinin bu görece az ele alınmış kısmını aydınlatmada Rus arşivleri bu kadar zengin malzeme sunabiliyorken, Türkiye' deki Cumhuriyet Arşivi'nin bu derece sınırlı belge barındırması ve böyle bir çalışmaya önemli hiçbir katkı sunamaması başlı başına düşündürücüdür.

Bilgiç'in çalışmasının belki en önemli katkısı, ilgili dönemde Türk Sovyet ilişkilerinin esasen iktisadi temelde şekillendiğini ortaya koymasıdır. İktisadi ilişkilerin somut ve detaylı bir dökümüyle güçlenen bu kanının, Türk Sovyet ilişkilerinin doğru anlaşılmasında kilit bir rolü olabileceği düşünülmelidir.

Türk Sovyet ilişkileri konusundaki geniş literatürde yapılan kimi değerlendirmeler iki savaş arası dönemdeki yakınlaşmayı ideolojik temelde açıklamaktadır. Emperyalizm karşıtlığı, Batı karşıtlığg gibi çeşitli biçimlerde ifade edilebilen yakınlaşmanın, iki rejimin kurucu ideolojileri arasındaki yakınlıktan ya da ortak tehditlerden kaynaklandığ savunulmaktadır. Öte yandan ilişkilerin gerildiği dönemlere ve özellikle 1945 toprak talepleri tartışmalarına odaklanan ve iki rejim arasındaki ilişkiyi tamamen güvenlik temelinde ele alan bir yaklaşım da mevcuttur. Soğuk savaş dönemi siyasi ortamının ya da 
iki ülke arasındaki köklü gerilimlerin de etkisiyle bu yaklaşımın, Erken Cumhuriyet dönemindeki yakınlaşmanın boyutlarını görmezden geldiği söylenebilir. Bu yaklaşıma göre 1945 ve sonrasına tarihlenen çatışma konuları mukadder gibidir; 1920'ler ve 1930'lardaki geçici yakınlaşma dönemi de bu yüzden ihmal edilebilir bir duruma gelmekte, özellikle Milli Mücadele dönemindeki yakınlaşma yalnızca stratejik bir tercihe indirgenmektedir. Böylece iki ülke arasındaki yakınlaşmayı tamamen ideolojik bir çerçevede kavrayan ya da tam tersi ideolojik sebeplerle görmezden gelmeye eğilimli iki hattın bulunduğu söylenebilir.

Bilgiç'in kitabı, Türk-Sovyet yakınlaşmasının her şeyden önce iktisadi bir yakınlaşma olduğunu ve ideolojik, jeopolitik ya da güvenlik yönlerinden önce ekonomik yönden anlaşılması gerektiğini ortaya koymaktadır. Cihan Harbi'nde durma noktasına gelen Karadeniz ticaretinin Sovyet devriminden sonra yelkenli gemilerle tekrar başlaması, her iki ülkenin de içinde bulunduğu yıkımın ve bu yıkımdan çıkıp toparlanmak için ticarete duydukları ihtiyacın boyutlarını ortaya koymaktadır.

\section{Kitabın Tezleri ve Tartışmalar}

Erdal Bilgiç'in çalışmasının ortaya koydu olgular, öncelikle ilgili dönemde Türkiye ve Rusya arasındaki ilişkilerin aldığı biçimin hiçbir şekilde durağan olmadığını göstermektedir. Erken Cumhuriyet dönemi boyunca ilişkiler gelgitlerle şekillenmiş ve çeşitli krizler ve çözümler barındırmıştır. Örneğin Türkiye'nin Batılı devletlere karşı kapitülasyonları kaldırma konusunda gösterdiği bilinen hassasiyeti, Sovyetler Birliği ile iktisadi ilişkilerinde bir kriz yaratmıştır. Sovyetler Birliği kapitülasyonların kaldırılmasını prensip olarak kabul etmiş olduğu halde, Türkiye Sovyetlerin devlet tarafından kontrol edilen ticari girişimlerini ve buna bağlı kimi talepleri bir tür kapitülasyon olarak yorumlamış ve buna karşı önlemler almıştır. Öyle ki iktisadi ilişkiler devlet kararıyla tamamen askıya da alınmıştır. Bu temel problem iki ülke arasındaki ticaretin biçimini şekillendirmiştir: Sorunun hukuki bir zeminde çözülmesinde merkezi bir rol oynayan Arcos şirketi ve faaliyetleri, kitapta da önemli bir yer tutmaktadır. Böylece kapitülasyonların şu veya bu formda geri dönmesi olasılığının genç Cumhuriyet'in en önemli kaygılarından olduğu, Bilgiç'in anlatısından ortaya çıkmaktadır.

Eser, 1930'lu yıllarda Doğu Anadolu'da Sovyet iktisadi faaliyetlerinin de Türkiye tarafından zaman zaman kaygıyla izlendiğini aktarmaktadır. Türkiye'nin kaygısının sebepleri, kısmen Sovyetlerin bölge ekonomisinde kazandığı ağırlıkla, kısmen de bu ticari bağların bölge tüccarlarının zararına olduğu düşüncesiyle alakalıdır. Bilgiç’in aktardığına göre duyulan güvensizlik, Sovyetlerin doğuda görev yapan personellerinin ajan 
olmakla suçlanmasına kadar varmıştır. Öte yandan Sovyetlerle yapılan ticaretin avantajlarının da farkında olunması, rejimi Sovyetlerin ticari faaliyetlerini iki yönüyle de değerlendirmeye itmiştir.

Bilgiç’in çalışmasının okuyucuya sunduğu iki önemli noktaya eğilmek önemli olacaktır. Birincisi, Türkiye'nin Sovyet iktisadi hedefleri açısından taşıdığı önemdir. Sovyet yetkililerinin Doğu Anadolu'daki eski Çarlık ticaret ağının farkında oldukları ve bu pazarda yeniden aktif olarak burada Batılılara üstünlük kurmayı amaçladıkları aktarılmaktadır. Nitekim üst düzey bir Sovyet yetkilisi (Çiçerin) coğrafi üstünlüğe sahip olan tarafin ticari üstünlüğe de sahip olması gerektiğini ileri sürmektedir.

İkinci önemli nokta ise, Sovyetlerin Türkiye coğrafyasına dair algısının ticari önemi üzerinden şekillendiğidir. Bilgiç’in aktarımına göre Sovyetler, Türkiye'yi doğu ve batı olarak iki ayrı ticari bölge gibi görme eğilimindedir. Her ikisindeki iktisadi ve ticari faaliyetlerin farklı Sovyet kurumlarınca icra edildiği ve hatta bu kurumlar arasında rekabet olduğu, Bilgiç’in vardığı ilginç sonuçlardan biridir. Bilgiç ayrıca, bu ticaretin Sovyet kurumlarına zarar da verdiğini aktarmaktadır.

Bilgiç’in bu aktarımları, yalnızca Türk Sovyet ilişkilerinin lineer ve stabil biçimde tasvir edilmesinin değil, Türkiye ve Sovyet iktisadi aktörlerinin mono-blok yapılar olarak algılanmasının da yanlışlığını ortaya koymaktadır. Bir bakıma Çarlık ve Sovyet yetkililerinin Türkiye ile ticarete bakışında süreklilik öne çıkarken, bir başka açıdan ise Sovyetler Birliği gibi merkezi kontrolü güçlü bir ekonomik sistemin, tek bir ülkeyle olan iktisadi ilişkilerinde bile birbiriyle çatışan yapılar ortaya çıkabildiği görülmektedir.

Bilgiç’in kitabında kendini gösteren en temel etmen ise iki ülkenin ilgili dönemde birbirilerine duydukları ihtiyaçtır. Bilgiç Sovyetler Birliği’nin Doğu Anadolu'daki dış ticarette hâkim ülke olduğu tespitinde bulunurken, pek çok doğu iline demir yolu bağlantısı olmadığından, bu illerin ürün tedariklerinin Batum limanın bağımlı olduğunu da aktarmaktadır. Batum ve Artvin ekonomilerini birbirinden bağımsız düşünmenin mümkün olmadığı Bilgiç tarafından vurgulanmaktadır.

Öte yandan İstanbul Limanı'nın Sovyetler Birliği için merkezi önemde olduğu da görülmektedir. İstanbul bir yandan Sovyet malları için hayati önemde bir ihracat limanı, bir yandan ise özellikle kıtlık dönemlerinde tahılın tedarik edilebildiği bir geçiş noktasıdır. Çalışmada iki taraf için de karşılıklı iktisadi ilişkilerin önemi ortaya konulmaktadır. Nitekim Cihan Harbi döneminde ticaretin durma noktasına gelmesinin sonuçları da bilinmektedir. 
Burada ilginç bir nokta, petrol ürünleri konusunda iki ülkenin ticaret potansiyellerini tam olarak kullanamamış olmalarıdır. Bilgiç, Türkiye petrol ürünleri piyasasında Sovyetlerin önemli bir pay alabileceğini, ancak Türkiye'nin limanlarında ürün boşaltılacak ve depolayacak alanlar olmamasının bunu çok zorlaştırdığını aktarmaktadır. İlgili eksiklik yüzünden petrol ürünleri ancak bidonlanarak satılabilmiştir. Bu yüzden petrol sendikası batılı rakiplerinin (Standard Oil) teknik altyapısına başvurmak zorunda kalmiştır.

İki ülkenin iktisadi ilişkilere duydukları karşılıklı ihtiyaç, Büyük Buhran ile değişen koşullarla da birleşerek 1930'lu yılların güçlü ekonomik yakınlaşmasının temelini atmıştır. Bilgiç, Sovyetlerin Türkiye'yi sadece pazar olarak değil, Kuzey Afrika ve Ortadoğu'ya uzanmanın yolu olarak da gördügüün̈ belirtmektedir. Buna karşılık Türkiye de 1930’ların değişen koşullarına aktif bir reaksiyon göstermiş, yeni iktisadi kurumlar aracılığıyla dış ticaretini kontrol etme çabasında olmuştur.

İki ülkenin dış ticaretlerini dengeli bir biçimde kontrol etme çabalarının, aynı zamanda güçlü bir birlikte çalışma kültürü yarattığg da anlaşılmaktadır. Bilgiç, 1920’li ve 1930’lu yıllar arasında açık bir fark olduğu görüşündedir: “1920'lerin dağınık ve birbirini suçlayan kurum raporlarının yerini üç aylık hazırlanan ayrıntılı ithalat ve ihracat raporları almıştır.” Birlikte çalışma konusunda kazanılan birikim ve kurumsallaşma deneyimi, iki ülkenin iktisadi ilişkilerinde açıkça görülebilir duruma gelmiştir.

\section{Tartışma ve Sonuç}

Erdal Bilgiç'in çalışması, gerek birçoğu daha önce kullanılmamış arşiv belgelerine dayanan yapısıyla, gerekse literatürde görece ihmal edilen bir alanı doldurmasıyla önem kazanmaktadır. Ancak çalışmanın önemi yalnızca buradan gelmemektedir; belki daha önemli nokta, Türkiye'de tartışmalı bir konu olan Türk-Sovyet ilişkilerine somut ve sağlam bir temel kazandırabilmiş olmasıdır. Konunun ideolojik, jeopolitik, askeri ya da güvenlik merkezli açılımları ne olursa olsun, iki ülkenin Erken Cumhuriyet döneminde kurduğu bağın öncelikle iktisadi temelde anlaşılması gereklidir. Bilgiç’in çalışması da bu anlamda, Türk-Sovyet ilişkilerini farklı yönleriyle ele alacak herkesin mutlaka temas etmesi gereken bir kaynak olacaktır. Bir başka açıdan ise eser, ilgili dönemde gerek Türk iktisadi tarihi, gerekse Sovyetler Birliği iktisadi tarihi çalışanlarca başvurulacak bir konumdadır.

Kitapta Erdal Bilgiç’in “İki Savaş Arası Dönemde Türk-Alman Ekonomik İlişkileri” üzerine de bir doktora tezi yazmakta olduğu belirtildiğinden, okur açısından ortaya 
doğal bir talep çıkmaktadır. Aynı dönemde Türkiye'nin Avrupa ve dünya sahnesinin iki büyük aktörüyle ekonomik ilişkileri üzerine iki ayrı doktora tezi hazırlayan yazarın, bu iki unsuru karşılaştırmalı olarak ele alması. Diğer bir deyişle Türkiye'nin Almanya ve Sovyetler ile olan ekonomik ilişkilerinin mukayesesinden çıkacak sonuçların ayrı bir başlıkta incelenmesi. Kuşkusuz bunun, burada ele alınan çalışmanın bir eksikliği olduğu söylenemez. Bilgiç'in çalışması, kendi amaçları açısından fazlasıyla başarılı bir çalışmadir. 